\title{
Phosphatase of regenerating liver-3 directly interacts with integrin $\beta 1$ and regulates its phosphorylation at tyrosine 783
}

Wei Tian', Like Qu', Lin Meng ${ }^{1}$, Caiyun Liu', Jian Wu' and Chengchao Shou ${ }^{1,2^{*}}$

\begin{abstract}
Background: Phosphatase of regenerating liver-3 (PRL-3 or PTP4A3) has been implicated in controlling cancer cell proliferation, motility, metastasis, and angiogenesis. Deregulated expression of PRL-3 is highly correlated with cancer progression and predicts poor survival. Although PRL-3 was categorized as a tyrosine phosphatase, its cellular substrates remain largely unknown.

Results: We demonstrated that PRL-3 interacts with integrin $\beta 1$ in cancer cells. Recombinant PRL-3 associates with the intracellular domain of integrin $\beta 1$ in vitro. Silencing of integrin a1 enhances PRL-3-integrin $\beta 1$ interaction. Furthermore, PRL-3 diminishes tyrosine phosphorylation of integrin $\beta 1$ in vitro and in vivo. With site-specific anti-phosphotyrosine antibodies against residues in the intracellular domain of integrin $\beta 1$, tyrosine-783, but not tyrosine-795, is shown to be dephosphorylated by PRL-3 in a catalytic activity-dependant manner. Phosphorylation of Y783 is potentiated by ablation of PRL-3 or by treatment with a chemical inhibitor of PRL-3. Conversely, depletion of integrin a1 decreases the phosphorylation of this site.
\end{abstract}

Conclusions: Our results revealed a direct interaction between PRL-3 and integrin $\beta 1$ and characterized Y783 of integrin $\beta 1$ as a bona fide substrate of PRL-3, which is negatively regulated by integrin $\alpha 1$.

Keywords: PRL-3, tyrosine phosphatase, integrin $\beta 1$, dephosphorylation

\section{Background}

PRL-3, a non-receptor tyrosine phosphatase containing a CAAX motif for prenylation at the carboxyl terminus [1], was found to be up-regulated in various types of malignancy, including colorectal, gastric, ovarian and breast cancers [2-5]. It has been shown to play a causal role in tumor metastasis by enhancing cancer cell motility and in tumor angiogenesis by recruiting endothelial cells [2]. PRL-3 expression is correlated with disease progression and poor survival [3-8], and its antibody was shown to dramatically inhibit metastatic tumor formation in human ovarian cancer cells [9], therefore it had been

\footnotetext{
* Correspondence: scc@bjcancer.org

'Key Laboratory of Carcinogenesis and Translational Research (Ministry of Education), Department of Biochemistry and Molecular Biology, Peking University Cancer Hospital \& Institute, Beijing, China

${ }^{2}$ Department of Biochemistry and Molecular Biology, Peking University

Cancer Hospital \& Institute, 52 Fucheng Road Haidian District, Beijing 100142, China
}

\section{Biomed Central}

(c) 2012 Tian et al.; licensee BioMed Central Ltd. This is an Open Access article distributed under the terms of the Creative Commons Attribution License (http://creativecommons.org/licenses/by/2.0), which permits unrestricted use, distribution, and reproduction in any medium, provided the original work is properly cited. deemed as a potential therapeutic target for the treatment of cancer [10].

PRL-3 could down-regulate PTEN expression and activate the PI3K pathway to promote epithelial-mesenchymal transition (EMT), thus contributing to tumor metastasis [11]. It has been implicated in controlling integrin-Src signaling pathway, in which ectopic PRL-3 promoted Src activation and potentiated Src-modulated oncogenic pathways, including ERK1/2, STAT3, and p130Cas [12]. PRL-3 was also shown to be a negative regulator of tumor suppressor p53 [13]. As a phosphatase, few PRL-3 substrates had been characterized, including Ezrin [14] and cytokeratin 8 [15], however, the cellular substrates of PRL-3 remain largely unknown.

Integrins are a large family of trans-membrane proteins, which are broadly involved in regulation of cell adhesion, motility and other physical and pathological processes [16,17]. Engagement of intergrins with their ligands stimulates diverse intracellular signaling pathways, such as tyrosine phosphorylation and activation of 
mitogen-activated protein kinases $[18,19]$. Integrin $\alpha 1$ and $\beta 1$ are known to heterodimerize to form the receptor for extracellular matrix (ECM), which is prerequisite for downstream signaling [17]. We previously identified integrin $\alpha 1$ as an interacting protein of PRL-3 through yeast two-hybrid screening, and PRL-3 could downregulate the tyrosine-phosphorylation level of integrin $\beta 1$ [20]. Furthermore, we showed the critical role of integrin $\beta 1$-ERK1/2-MMP2 signaling in PRL-3-promoted motility, invasion, and metastasis of colon cancer cells [21]. In this study, we demonstrate that PRL-3 directly binds to integrin $\beta 1$ and dephosphorylates integrin $\beta 1$ $Y 783$, a key residue for integrin $\beta 1$ function [22]. Moreover, we show that integrin $\alpha 1$ inhibits the PRL-3/integrin $\beta 1$ interaction and the dephosphorylation of integrin $\beta 1$ Y783 by PRL-3.

\section{Results}

Direct interaction between PRL-3 and integrin $\beta 1$, which is regulated by integrin $a 1$

Our previous findings of integrin $\alpha 1$ as a binding partner of PRL-3 [20] and integrin $\beta 1-E R K 1 / 2-M M P 2$ signaling mediating PRL-3-promoted cell invasion and metastasis [21] prompted us to further dissect the relationship between PRL-3 and integrins. As an initial step, we examined their expression levels in human gastric cancer cell line BGC823 and colon cancer cell lines SW480, LoVo, and HCT116. Figure 1A shows that integrin $\beta 1$ was expressed in all these cell lines, but integrin $\alpha 1$ was only detected in BGC823 cells. In addition, relatively high expression of PRL-3 was found in BGC823 and SW480 cells (Figure 1A). Next, coimmunoprecititation assay was performed with protein lysates from BGC823 cells and SW480 cells. In both cell lines, endogenous integrin $\beta 1$ was detected in anti-PRL-3 precipitates (Figure 1B). Furthermore, GST pull-down assay was performed with bacterially expressed His-tagged PRL-3 and GST-fused intracellular domain of integrin $\beta 1$ (752798aa). The result shows that His-PRL-3 could be precipitated by GST-intergrin $\beta 1$, but not by GST (Figure 1C). Thus, PRL-3 directly interacts with integrin $\beta 1$.

Since integrin $\alpha 1$ heterodimerizes with integrin $\beta 1$ [16] and our previous study revealed an integrin $\alpha 1-\mathrm{PRL}-3$ interaction [20], we then investigated whether integrin $\alpha 1$ plays a role in modulating PRL-3-integrin $\beta 1$ interaction. We transfected integrin $\alpha 1$-specific siRNA or control siRNA into integrin $\alpha 1$-proficient BGC823 cells, and performed co-immunoprecipitation assay. As shown in Figure $2 \mathrm{~A}$, more integrin $\beta 1$ was precipitated by antiPRL-3 antibody upon integrin $\alpha 1$-silencing. In addition, we carried out immunoflorescence assay to examine the

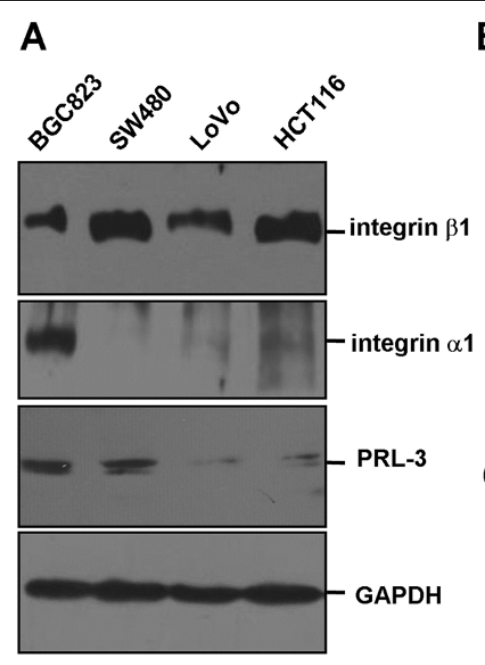

B
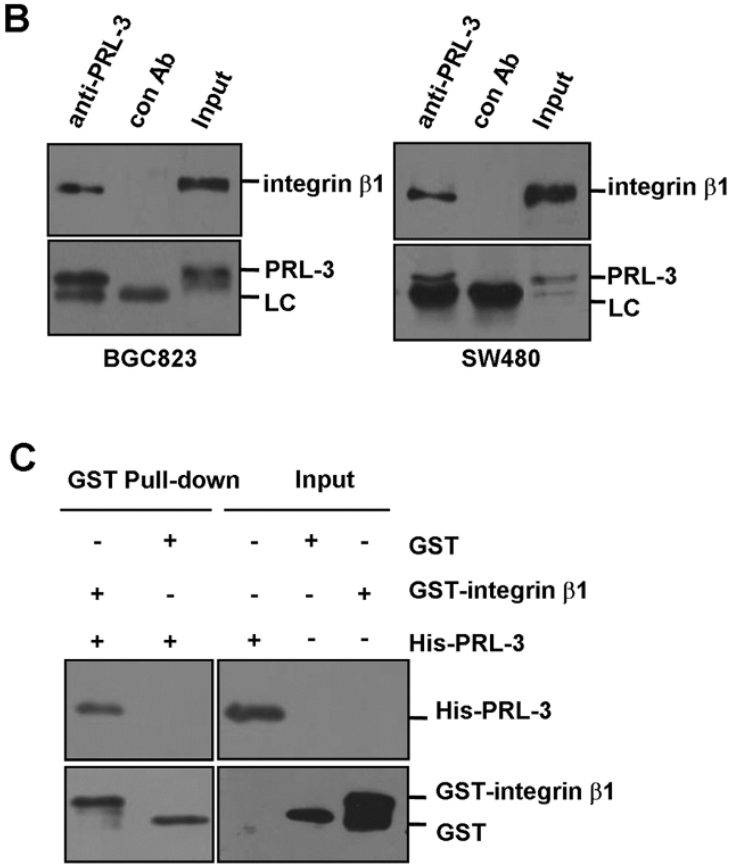

Figure 1 Physical interaction between PRL-3 and integrin $\beta 1$. (A) The expression profiles of integrin $\beta 1$, integrin a1 and PRL-3 in different cell lines. Equal amount of protein lysates from indicated cells were subjected to Western blotting with integrin $\beta 1$, integrin a1and PRL-3 antibodies. GAPDH protein expression was shown as loading control. (B) Endogenous interaction between PRL-3 and integrin $\beta 1.500 \mu \mathrm{g}$ of lysates from BGC823 (left panel) or SW480 (right panel) cells were immunoprecipitated with $1 \mu \mathrm{g}$ PRL-3 monoclonal antibody or $1 \mu \mathrm{g}$ pre-immune mouse lgG (control), followed by Western blotting with integrin $\beta 1$ and PRL-3 antibodies. Expression of integrin $\beta 1$ and PRL-3 in the lysates (50 $\mu \mathrm{g}$ ) was shown as input. (C) Direct interaction between PRL-3 and integrin $\beta 1$. GST-integrin $\beta 1$ (intracellular domain, 752-798aa) and His-tagged PRL-3 were expressed respectively and used for in vitro pull-down assay. 


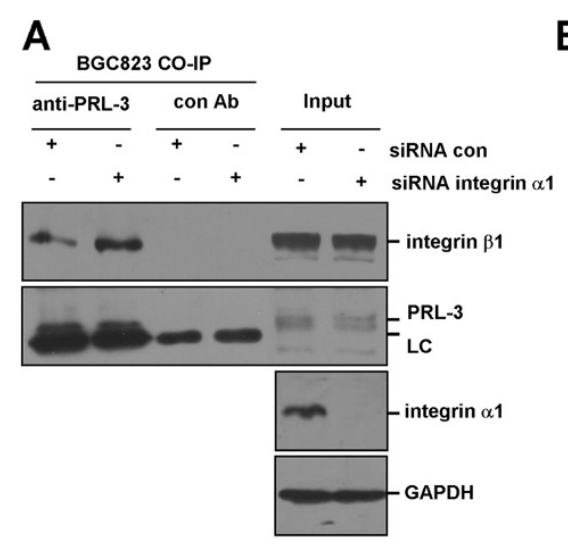

\section{B}

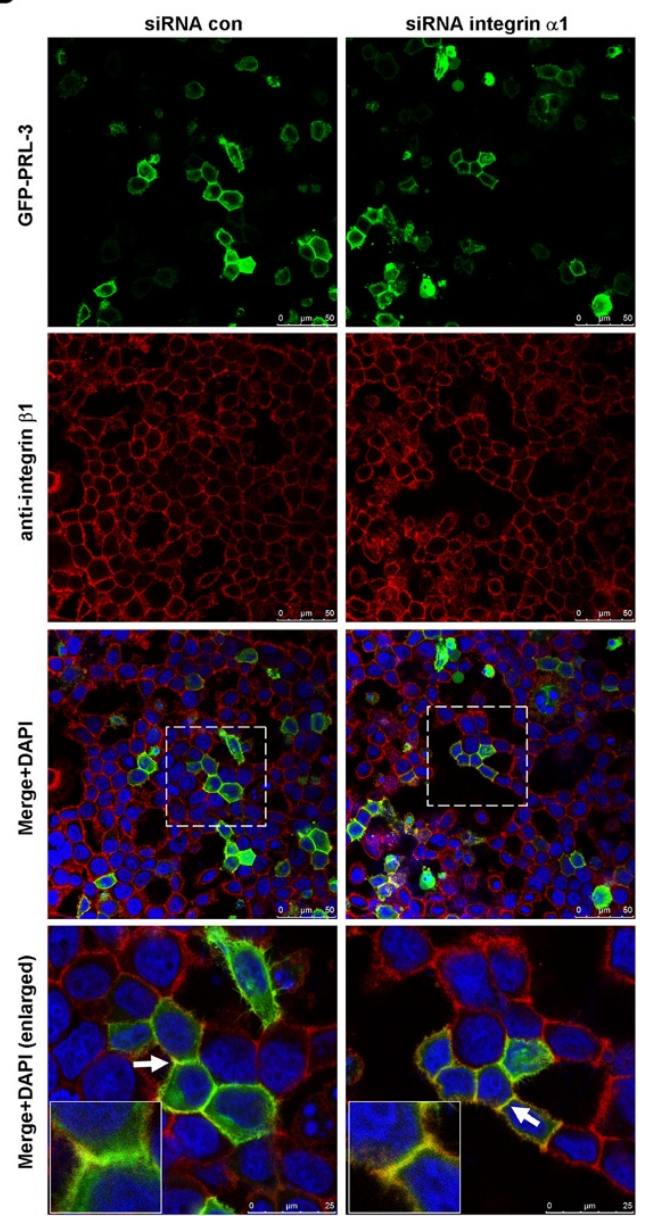

Figure 2 Physical interaction between PRL-3 and integrin $\beta 1$. (A) Deletion of integrin a1 resulted in enhanced PRL-3-integrin $\beta 1$ interaction. BGC823 cells were transfected with $100 \mathrm{pmol}$ integrin a1-specific siRNA or control siRNA for $48 \mathrm{hr}$. $500 \mathrm{\mu g}$ protein lysates were incubated with PRL-3 antibody or pre-immune mouse lgG (control) for co-immunoprecipitation assay. The immunoprecipitates and $50 \mu \mathrm{g}$ protein lysates (input) were immunoblotted by integrin $\beta 1$ and PRL-3 antibodies. Efficiency of intergrin a1 silencing in the input was verified. "LC" is short for light chain of antibody. (B) PRL-3 co-localized with integrin $\beta 1$ in an integrin a1-independent manner. After being transfected with 100 pmol integrin a1 siRNA and control siRNA for 24 hours, BGC823 cells were transfected with $2 \mu \mathrm{g}$ GFP-PRL-3, and cultured for another 24 hours, then fixed, blocked, and immunostained with anti-integrin $\beta 1$ antibody. Localization of GFP-PRL-3 (green) and integrin $\beta 1$ (red) was detected by a laser confocal microscope. Parts of merged images were enlarged (white rectangles) to show the co-localization between two molecules (yellow). The white arrows labeled regions were further enlarged (insert).

co-localization between GFP-PRL-3 and endogenous integrin $\beta 1$. GFP-PRL-3 and integrin $\beta 1$ partially colocalized on the punctate structures of cell membrane in control siRNA-transfected cells. However, knockdown of integrin $\alpha 1$ resulted in an increase in the co-localization between GFP-PRL-3 and integrin $\beta 1$ (Figure 2B). These findings suggest that integrin $\alpha 1$ negatively regulates association between PRL-3 and integrin $\beta 1$.

\section{In vitro and in vivo dephosphorylation of integrin $\beta 1$ by}

\section{PRL-3}

Since PRL-3 directly interacts with integrin $\beta 1$, we further investigated if integrin $\beta 1$ is a substrate of PRL-3 phosphatase. We expressed and purified GST-fused wild- type PRL-3 and the PRL-3-mt, in which the phosphatase activity was eliminated by mutating cystine 104 to serine [12,23] (Figure 3A). In vitro dephosphorylation assay was performed with GST-PRL-3 and GST-PRL-3-mt plus equal amount of immunoprecipitated endogenous integrin $\beta 1$ as substrate. We found wild-type GST-PRL-3 significantly decreased the tyrosine phosphorylation of integrin $\beta 1$, whereas mutant GST-PRL-3 had no obvious effect (Figure 3B).

Moreover, we examined if such regulation occurs in vivo. We introduced myc-PRL-3 into BGC823 and HCT116 cells. As controls, the cells were transfected with vector alone. Immunoblot analysis revealed that ectopic expression of myc-PRL-3 considerably decreased 


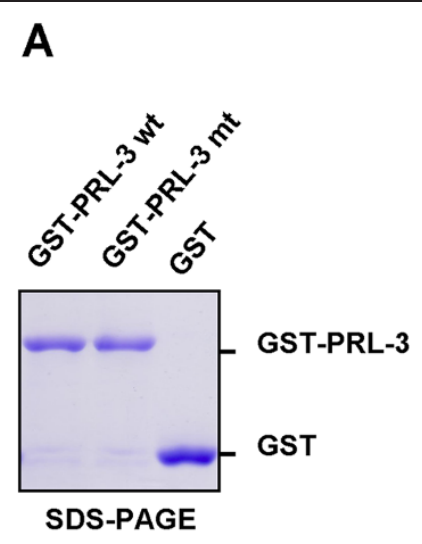

B

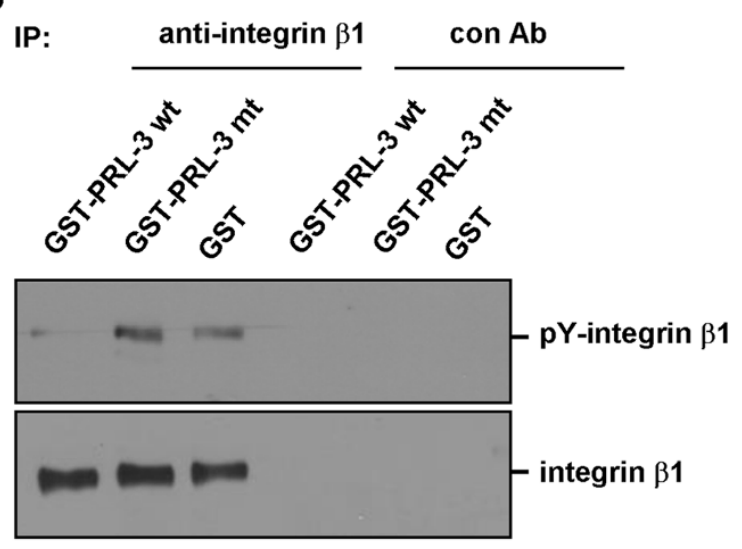

In vitro phosphatase assay

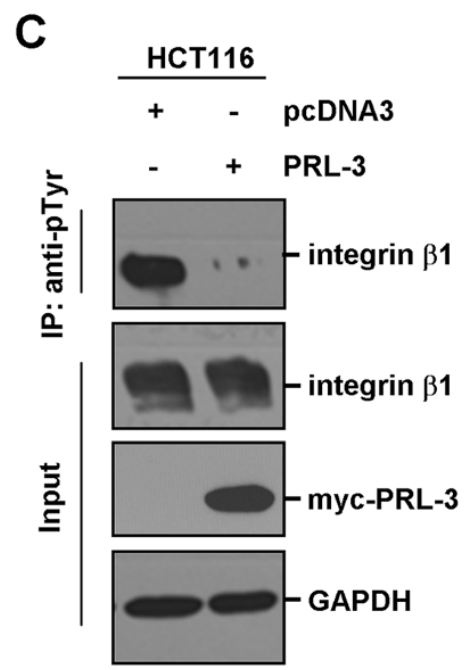

In vivo phosphatase assay

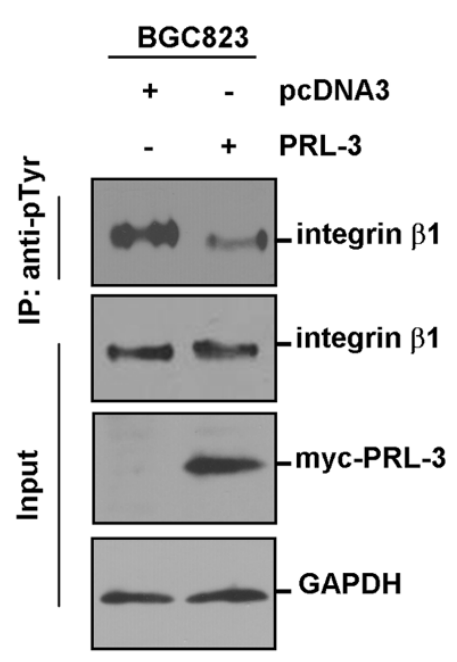

In vivo phosphatase assay

Figure 3 In vitro and in vivo dephosphorylation of integrin $\beta 1$ by PRL-3. (A) The purified GST-PRL-3, mutant GST-PRL-3 (GST-PRL-3-mt) and GST proteins were examined by SDS-PAGE and commassie blue staining. (B) Dephosphorylation of integrin $\beta 1$ by PRL-3 in vitro. $1000 \mu \mathrm{g} \mathrm{HCT116}$ cell lysates were immunoprecipitated with integrin $\beta 1$ antibody or control IgG. After sequential washing with lysis buffer and dephosphorylation buffer, the precipitates were used as substrates, and incubated with $1 \mu \mathrm{g}$ purified GST-PRL-3 wt, GST-PRL-3 mt or GST in the dephosphorylation buffer for $30 \mathrm{~min}$ at $30^{\circ} \mathrm{C}$, then the mixtures were analyzed by Western blotting with anti-phosphotyrosine (4G10) and anti-integrin $\beta 1$ antibodies. (C) Dephosphorylation of integrin $\beta 1$ in HCT116 (left panel) and BGC823 (right panel) cells by ectopic expression of PRL-3. Equal amount of lysates from cells over-expressing myc-PRL-3 and pcDNA3 (control) were immunoprecipitated with anti-phosphotyrosine (4G10) antibody, followed by immunoblotting with anti-integrin $\beta 1$ antibody. Expression of integrin $\beta 1$ and myc-PRL-3 in the lysates were indicated.

the phosphorylation of integrin $\beta 1$ at tyrosine residue(s), but did not affect total protein levels of integrin $\beta 1$ (Figure 3C). These results indicate that PRL-3 dephosphorylates integrin $\beta 1$ in vitro and in vivo.

\section{PRL-3 dephosphorylates tyrosine-783 of integrin $\beta 1$}

Previous study reported that phosphorylation of Y783 and/or Y795 in the cytoplasmic domain of integrin $\beta 1$ may be essential for its function [24]. We next investigated whether PRL-3 dephsohorylates Y783 and/or Y795. BGC823 cells and SW480 cells were transfected with myc-tagged wild-type PRL-3 and PRL-3-mt.
Immunoblot analysis revealed that ectopic expression of PRL-3, but not PRL-3-mt, significantly reduced pY783 of integrin $\beta 1$ in both cell lines (Figure 4A), while pY795 were undetectable (data not shown). We also knocked down endogenous PRL-3 and found that depletion of PRL-3 could markedly increase pY783 levels in BGC823 cells (Figure 4B). To further validate PRL-3-mediated dephosphorylation of Y783 of integrin $\beta 1$, chemical inhibitor of PRL-3 (P0108), which has been shown to specifically inhibit PRL-3 phosphatase activity and decrease PRL-3-mediated cancer cell migration and invasion $[15,25]$, was used to treat BGC823 and SW480 cells. 


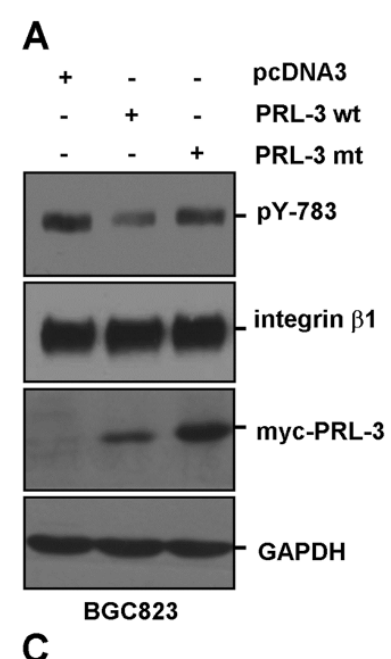

C
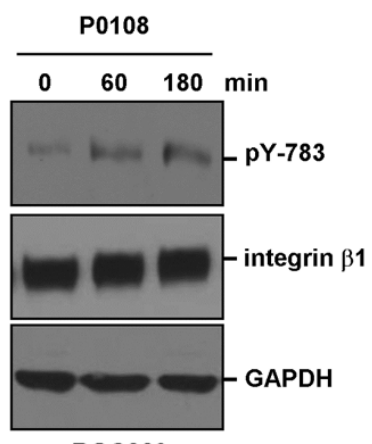

BGC823

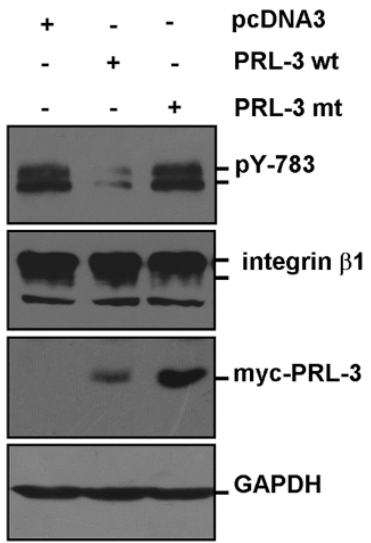

SW480

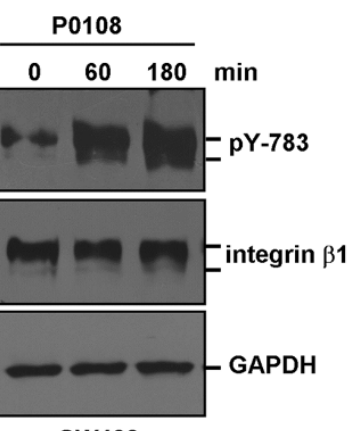

SW480

B

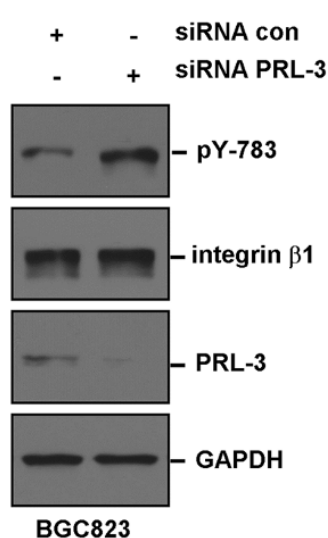

E
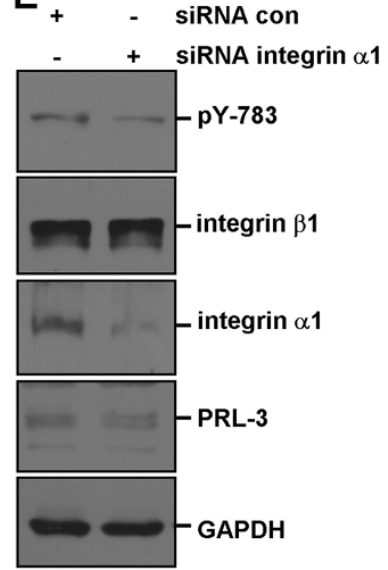

BGC823

D Provanadate
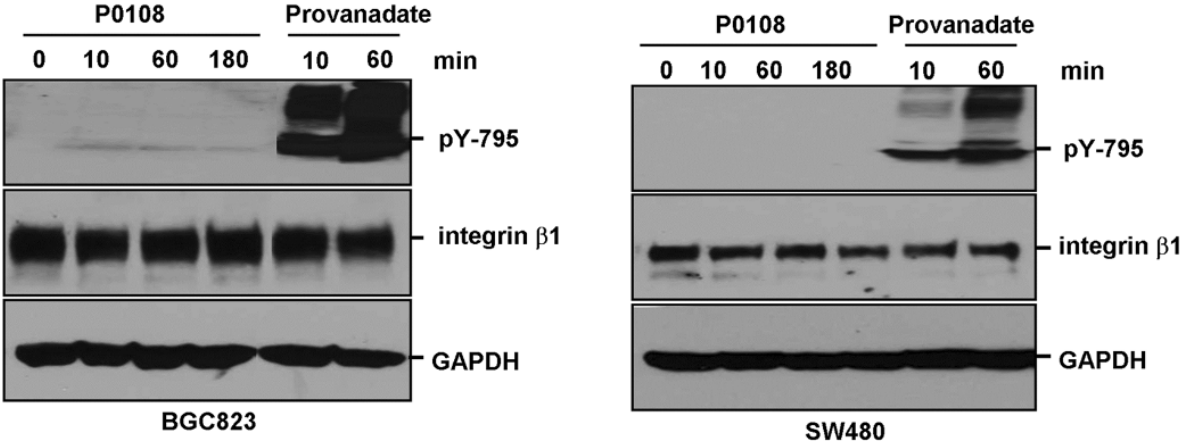

Figure 4 Regulation of integrin $\beta 1$ phosphorylation at tyrosine 783 by PRL-3. (A) Wild-type myc-PRL-3, but not mutant myc-PRL-3 dephosphorylated tyrosine 783 of integrin $\beta 1$ in BGC-823 (left panel) and SW480 cells (right panel). After transfection with myc-PRL-3, myc-PRL-3mt or pcDNA3 (control) plasmids, equal amount of cell lysates were analyzed by Western blotting with antibodies against pY783, integrin $\beta 1$, myc and GAPDH. (B) Knockdown of PRL-3 promoted pY783 phosphorylation. BGC823 cells were transfected with 100 pmol indicated siRNA for 48 hours, and the cell lysates were analyzed by Western blotting with indicated antibodies. (C) PRL-3 inhibitor enhanced pY783 phosphorylation. BGC823 (left panel) and SW480 cells (right panel) were treated with $10 \mu \mathrm{g} / \mathrm{ml} \mathrm{PRL-3} \mathrm{inhibitor.} \mathrm{Cells} \mathrm{were} \mathrm{harvested} \mathrm{at} \mathrm{different} \mathrm{time} \mathrm{points} \mathrm{and}$ protein lysates were analyzed by Western blotting with indicated antibodies. (D) PRL-3 had minimal effect on pY795 of integrin $\beta 1$. BGC823 (left panel) and SW480 cells (right panel) were treated with $10 \mu \mathrm{g} / \mathrm{ml} \mathrm{PRL-3} \mathrm{inhibitor} \mathrm{or} 100 \mu \mathrm{M}$ provanadate (as positive control). Protein lysates were harvested at indicated time points and analyzed by Western blotting. (E) Knockdown of integrin a1 decreased pY783 phosphorylation. BGC823 cells were transfected with integrin a1-specific siRNA or control siRNA for 72 hours, and the lysates were analyzed by Western blotting. 
Increment of pY783 levels in both cell lines was observed after P0108 treatment (Figure 4C). P0108 had a marginal stimulatory effect on pY795 in BGC823 cells, but pY795 could be strongly enhanced by treatment with tyrosine phosphatase inhibitor pervanadate in both BGC823 and SW480 cells (Figure 4D). In line with enhanced PRL-3-integrin $\beta 1$ interaction upon silencing of integrin $\alpha 1$ (Figure 2A and B), pY783 was decreased by ablation of integrin $\alpha 1$ (Figure 4E). Collectively, these results show that PRL-3 dephosphorylates integrin $\beta 1$ at tyrosine-783, but not tyrosine-795.

\section{Discussion}

Protein kinases and phosphatases play important roles in diverse physiological processes and diseases [26-28]. PRL-3, as a member of protein phosphatases, has been found to promote cancer cell invasiveness [10,29-32]. However, the underlying mechanism remains elusive. In the present study, we demonstrate that PRL-3 directly binds to integrin $\beta 1$ and dephosphorylates integrin $\beta 1$ Y783. Furthermore, we found that deletion of integrin $\alpha 1$ resulted in increased PRL-3-integrin $\beta 1$ association and decreased phosphorylation of integrin $\beta 1-Y 783$. These findings indicate that integrin $\beta 1$ is a bona fide substrate of PRL-3 and raise the possibility that integrin $\alpha 1$ may function as a negative regulator for PRL-3integrin $\beta 1$ interaction.

Previous studies have shown that integrin $\beta 1-Y 783$ and -Y795 are parts of conserved NPxY motifs essential for recruiting talin and kindlin, which in turn facilitates coupling of integrin $\beta 1$ to the actin cytoskeleton and maintains integrins in an active signaling state [33]. It was reported that $\mathrm{v}$-Src could phosphorylate integrin $\beta 1$ tails on Y783 and Y795 [34,35], and that phosphorylated Y783 and Y795 could block talin and kindlin's binding with integrin $\beta 1$, respectively [36,37]. These were supported by the study that $\mathrm{v}$-Src expression in fibroblasts decreases integrin $\beta 1$-dependent adhesion, focal adhesion formation, cytoskeletal organization, fibronectin assembly, migration, and chemotaxis [34,38]. While several kinases, including Src, have been shown to phosphorylate Y783 and Y795 [34,35], the phosphatase(s) catalyzing the de-phosphorylation of these two sites is unknown. By showing PRL-3 is responsible for dephosphorylating pY783, our present results provide an explanation for the delicate control of integrin $\beta 1$.

It is noted that a recent study showing the short phosphotyrosine peptides encompassing Y783 or Y795 of integrin $\beta 1$ could not be dephosphorylated by PRL-3 in an in vitro assay [39]. However, as the author suggested, this could be explained by lack of entire integrin $\beta 1$ to be recognized by PRL-3 [39]. In our study, instead of using the synthesized peptides, we immunoprecipited the endogenous integrin $\beta 1$ as substrate for in vitro phosphatase assay, which ensures optimal phosphatasesubstrate association. In addition, we did not find alteration in pY795 by over-expression or ablation of PRL-3, which could be due to the fact that pY795 level is too low to be detected in the cancer cells examined. We did observe slightly more pY795 in PRL-3 inhibitor treated BGC823 cells, while such agent-induced changes of pY795 was not as robust as those of pY783 in BGC823 and SW480 cells. Interestingly, treatment with a panphosphatase inhibitor significantly elevates pY795, suggesting that PRL-3 may partially contribute to the dephosphorylation of pY795 and pY795 is mainly regulated by other phosphatase(s).

\section{Conclusion}

In summary, our results demonstrated a direct interaction between PRL-3 and integrin $\beta 1$, which could be negatively regulated by integrin $\alpha 1$. Importantly, we identified tyrosine 783 of integrin $\beta 1$ as a direct dephosphorylation site by PRL-3, thus uncovering the first tyrosine phosphorylation site to be regulated by PRL-3 phosphatase.

\section{Methods}

\section{Cell lines and Reagents}

Colon cancer cell lines LoVo, SW480 and HCT116 were obtained from ATCC (Manassas, VA) and maintained in DMEM (Invitrogen, Carlsbad, CA). Gastric cancer cell BGC823 was maintained in RPMI-1640 medium (Invitrogen). The medium was supplemented with $10 \%$ fetal calf serum (Invitrogen). The antibodies against integrin $\beta 1$ (MAB 2000), integrin $\alpha 1$ (MAB1973) and phosphorylated tyrosine (4G10) (16-316) were from Millipore (Billerica, MA). Anti-phosphorylated integrin $\beta 1$ (Tyr783) (600601) and (Tyr795) (600501) antibodies were obtained from Biolegend (San Diego, CA). Antibody against PRL-3 (clone 318) was from Santa Cruz (Santa Cruz, CA). GADPH antibody was from Proteintech Group (Chicago, IL). PRL3 inhibitor 1-(2-bromobenzyloxy)-4-bromo-2-benzylidene rhodanine (P0108) was from Sigma (St. Louis, MO). The tyrosine phosphatase inhibitor (Pervanadate) was freshly prepared by dissolving sodium orthovanadate (Sigma) with PBS to $30 \mathrm{mM}$, adding hydrogen peroxide at $0.18 \%$ $(\mathrm{v} / \mathrm{v})$, and incubating for $15 \mathrm{~min}$ at room temperature avoiding light before treating the cells at the final concentration of $100 \mu \mathrm{M}$.

\section{Plasmids transfection and RNA interference}

The plasmids expressing myc-PRL-3, myc-PRL-3-mt (cystine 104 was mutated to serine) and GFP-PRL-3 were described as previously [23]. The small interference RNAs (siRNAs) targeting integrin $\alpha 1$ and PRL-3 were synthesized by GenePharma (Shanghai, China), the sequence for integrin $\alpha 1$ : sense, 5'- GCCCUUAUAUGCCUAUAGA -3'; 
antisense, 5'- UCUAUAGGCAUAUAAGGGC -3'; the sequence for PRL-3: sense, 5'- CAGCAAGCAGCUCAC CUAC -3'; antisense, 5'- GUAGGUGAGCUGCUUGCUG -3 '. Plasmids and siRNA were transfected into cells with Lipofectamine 2000 (Invitrogen) following provider's instruction.

\section{Immunofluorescence}

To visualize the localization of integrin $\beta 1$, BGC823 cells were cultured on the coverslips and fixed with $2 \%$ paraformaldehyde for $30 \mathrm{~min}$ at $4{ }^{\circ} \mathrm{C}$, followed by permeabilization with $0.5 \%$ Triton $\mathrm{X}-100$ in PBS for $5 \mathrm{~min}$, and blocking with $3 \%$ bovine serum albumin overnight at $4^{\circ} \mathrm{C}$. After incubation with anti-integrin $\beta 1$ (1: 300) for $1 \mathrm{hr}$ at room temperature, cells were probed with tetramethyl rhodamine isothiocyanate-conjugated secondary antibody, counterstained with 4', 6-diamidino-2-phenylindole (DAPI), and mounted on $50 \%$ glycerol/PBS. Localization of PRL-3 was analyzed by transfecting the cells with pEGFP-PRL-3. A Leica SP2 confocal system (Leica Microsystems, Dresden, Germany) was used to observe the localization of integrin $\beta 1$ and GFP-PRL-3.

\section{Western blotting and immunoprecipitation}

For Western blotting, cells were directly lysed in $1 \mathrm{x}$ loading buffer. For immunoprecipitation assay, cells were homogenized in lysis buffer $(50 \mathrm{mM}$ HEPES $\mathrm{pH}$ 8.0, $150 \mathrm{mM}$ NaCl, 1 mM EDTA, 1\% Triton X-100, 10\% glycerol, $50 \mathrm{mM} \mathrm{NaF}, 1 \mathrm{mM} \mathrm{Na} \mathrm{VO}_{4}, 2 \mathrm{mM}$ dithiothreitol, $1 \times$ protease cocktail $\left(\right.$ Sigma)) for $20 \mathrm{~min}$ at $4^{\circ} \mathrm{C}$. The supernatant was collected after centrifugation at $12,000 \times \mathrm{g}$ for $20 \mathrm{~min}$ at $4^{\circ} \mathrm{C}$ and then incubated with indicated antibodies conjugated to protein G-Sepharose (Invitrogen). Cell lysates or immunoprecipitates were separated by SDS-PAGE and electro-blotted to the nitrocellulose membranes. Non-specific binding was blocked with $5 \%$ non-fat milk in PBS overnight at $4^{\circ} \mathrm{C}$ and was rinsed twice with PBST. Then the membranes were incubated with indicated primary antibodies at room temperature for $1.5 \mathrm{~h}$, and washed six times with PBST, followed by horseradish peroxidase-labeled secondary antibodies for $45 \mathrm{~min}$ and washed again as above. Protein bands were visualized with enhanced chemoluminescence system (Thermo Scientific, Rockford, IL).

\section{GST Pull-down assay}

Deoxyribonucleic acids encoding intracellular domain of integrin $\beta 1$ (752-798aa) was amplified by PCR with the following primers: sense, 5'- GACTGAATTCAAGCTTT TAATGATAATTCATG -3'; antisense, 5'- AGCAACTC GAGGTGTTGTGGGATTTGCAC -3'. The PCR product was digested by EcoR I/Xho I and inserted into pGEX4T1 vector. His-tagged PRL-3 was constructed by inserting the digested PRL-3 into pET-28a vector. For pull- down assay, glutathione-Sepharose beads (Invitrogen) were incubated with E. coli bacteria lysates expressing GST-integrin $\beta 1$ or GST. After being washed with PBS, these beads were incubated with His-PRL-3 in binding buffer $(10 \mathrm{mM}$ Tris- $\mathrm{HCl} \mathrm{pH}$ 8.0, $150 \mathrm{mM} \mathrm{NaCl}, 1 \mathrm{mM}$ dithiothreitol, $1 \mathrm{mM}$ PMSF, 1\% Triton X-100, 10\% glycerol) for 4 hours at $4^{\circ} \mathrm{C}$, then washed three times, boiled in SDS loading buffer, separated by SDS-PAGE and immunoblotted with PRL-3 and GST antibodies.

\section{In vitro phosphatase assay}

Integrin $\beta 1$ protein was immunoprecipitated from 1000 $\mu \mathrm{g}$ protein from HCT116 cell lysates with $1 \mu \mathrm{g}$ integrin $\beta 1$ antibody conjugated to protein G-Sepharose. For control, cell lysates were immunoprecipitated with $1 \mu \mathrm{g}$ pre-immune IgG. After being washed 3 times with lysis buffer, once with dephosphorylation buffer $(50 \mathrm{mM}$ Tris $\mathrm{pH}$ 7.5, $2 \mathrm{mM}$ dithiothreitol, $1 \mathrm{mM} \mathrm{MgCl}_{2}, 0.1 \mathrm{mM}$ $\mathrm{MnCl}_{2}$ ), the precipitates were used as substrate for in vitro phosphatase assay. GST-PRL-3, GST-PRL-3-mt, and GST (1 $\mu \mathrm{g}$ each) were used as phosphatase and incubated with substrate in $20 \mu \mathrm{L}$ dephosphorylation buffer at $30^{\circ} \mathrm{C}$ for $30 \mathrm{~min}$. The reaction was stopped by boiling in $2 \times$ loading buffer and the phosphorylated integrin $\beta 1$ was detected by immunoblotting with 4G10 antibody.

\section{Abbreviations}

PRL-3: Phosphatase of regenerating liver-3; PBS: Phosphate-buffered saline; SDS-PAGE: Sodium dodecyl sulfate polyacrylamide gel electrophoresis; siRNA: Small interference RNA; EMT: Epithelial-mesenchymal transition.

\section{Competing interests}

The authors declare that there are not any financial or non-financial competing interests associated with this work.

\section{Authors' contributions}

CS conceived the project. CS and LQ designed the experiments. WT, LM, CL, and JW performed the experiments. CS, LQ, and WT analyzed data. WT and LQ wrote the manuscript. All authors read and approved the final manuscript.

\section{Acknowledgement}

We deeply appreciate Dr. Jin Q. Cheng and Dr. Jianping Guo (H. Lee Moffitt Cancer Center and Research Institute, USA) for their generous help in the study and critical comments on the manuscript. We also appreciate Dr. Qi Zeng (Institute of Molecular and Cell Biology, Singapore) and Dr. Jianming Li (Southern Medical University, China) for helpful discussion and sharing unpublished data. This study was supported by the National Natural Science Foundation of China (81071732, 30973407) and National 973 Program of China (2009CB521805). The funders had no role in study design, data collection and analysis, decision to publish, or preparation of the manuscript.

Received: 10 July 2012 Accepted: 26 September 2012

Published: 23 October 2012

\section{References}

1. Zeng Q, Hong W, Tan YH: Mouse PRL-2 and PRL-3, two potentially prenylated protein tyrosine phosphatases homologous to PRL-1. Biochem Biophys Res Commun 1998, 244:421-427.

2. Guo K, Li J, Wang H, Osato M, Tang JP, Quah SY, Gan BQ, Zeng Q: PRL-3 Initiates Tumor Angiogenesis by Recruiting Endothelial Cells In vitro and In vivo. Cancer Res 2006, 66:9625-9635. 
3. Ren $T$, Jiang B, Xing X, Dong B, Peng L, Meng L, Xu H, Shou C: Prognostic Significance of Phosphatase of Regenerating Liver-3 Expression in Ovarian Cancer. Pathol Oncol Res 2009, 15:555-560.

4. Wang $L$, Peng L, Dong B, Kong L, Meng L, Yan L, Xie Y, Shou C: Overexpression of phosphatase of regenerating liver-3 in breast cancer association with a poor clinical outcome. Ann Oncol 2006, 17:1517-1522

5. Xing X, Peng L, Qu L, Ren T, Dong B, Su X, Shou C: Prognostic value of PRL-3 overexpression in early stages of colonic cancer. Histopathology 2009, 54:309-318.

6. Radke I, Götte M, Kersting C, Mattsson B, Kiesel L, Wülfing P: Expression and prognostic impact of the protein tyrosine phosphatases PRL-1, PRL-2, and PRL-3 in breast cancer. Br J Cancer 2006, 95:347-354.

7. Bardelli A, Saha S, Sager JA, Romans KE, Xin B, Markowitz SD, Lengauer C, Velculescu VE, Kinzler KW, Vogelstein B: PRL-3 expression in metastatic cancers. Clin Cancer Res 2003, 9:5607-5615.

8. Polato F, Codegoni A, Fruscio R, Perego P, Mangioni C, Saha S, Bardelli A, Broggini M: PRL-3 Phosphatase Is Implicated in Ovarian Cancer Growth. Clin Cancer Res 2005, 11:6835-6839.

9. Guo K, Tang JP, Tan CP, Wang H, Zeng Q: Monoclonal antibodies targe intracellular PRL phosphatases to inhibit cancer metastases in mice. Cancer Biol Ther 2008, 7:750-757.

10. Kato H, Semba S, Miskad UA, Seo Y, Kasuga M, Yokozaki H: High expression of PRL-3 promotes cancer cell motility and liver metastasis in human colorectal cancer: a predictive molecular marker of metachronous liver and lung metastases. Clin Cancer Res 2004, 10:7318-7328.

11. Wang H, Quah SY, Dong JM, Manser E, Tang JP, Zeng Q: PRL-3 Downregulates PTEN Expression and Signals through PI3K to Promote Epithelial-Mesenchymal Transition. Cancer Res 2007, 67:2922-2926.

12. Liang F, Liang J, Wang WQ, Sun JP, Udho E, Zhang ZY: PRL3 Promotes Cell Invasion and Proliferation by Down-regulation of Csk Leading to Src Activation. J Biol Chem 2006, 282:5413-5419.

13. Min S-H, Kim DM, Heo Y-S, Kim HM, Kim I-C, Yoo O-J: Downregulation of p53 by phosphatase of regenerating liver 3 is mediated by MDM2 and PIRH2. Life Sci 2010, 86:66-72.

14. Forte E, Orsatti L, Talamo F, Barbato G, De Francesco R, Tomei L: Ezrin is a specific and direct target of protein tyrosine phosphatase PRL-3. Biochim Biophys Acta 2008, 1783:334-344.

15. Mizuuchi E, Semba S, Kodama Y, Yokozaki H: Down-modulation of keratin 8 phosphorylation levels by PRL-3 contributes to colorectal carcinoma progression. Int J Cancer 2009, 124:1802-1810.

16. Varner JA, Cheresh DA: Integrins and cancer. Curr Opin Cell Biol 1996, 8:724-730.

17. Arnaout MA, Mahalingam B, Xiong JP: Integrin structure, allostery, and bidirectional signaling. Annu Rev Cell Dev Biol 2005, 21:381-410.

18. Liu S, Thomas SM, Woodside DG, Rose DM, Kiosses WB, Pfaff M, Ginsberg $\mathrm{MH}$ : Binding of paxillin to alpha4 integrins modifies integrin-dependent biological responses. Nature 1999, 402:676-681.

19. Tuckwell DS, Humphries MJ: Molecular and cellular biology of integrins. Crit Rev Oncol Hematol 1993, 15:149-171.

20. Peng $L$, Jin $G$, Wang $L$, Guo J, Meng $L$, Shou $C$ : Identification of integrin alpha1 as an interacting protein of protein tyrosine phosphatase PRL-3. Biochem Biophys Res Commun 2006, 342:179-183.

21. Peng L, Xing X, Li W, Qu L, Meng L, Lian S, Jiang B, Wu J, Shou C: PRL-3 promotes the motility, invasion, and metastasis of LoVo colon cancer cells through PRL-3-integrin $\beta 1$-ERK1/2 and-MMP2 signaling. Mol Cancer 2009, 8:110.

22. Sakai T, Zhang Q, Fassler R, Mosher DF: Modulation of beta1A integrin functions by tyrosine residues in the beta1 cytoplasmic domain. J Cell Biol 1998, 141:527-538

23. Li WJ, Xing XF, Qu LK, Meng L, Shou CC: Construction and expression of PRL-3 plasmid with C104S point mutation and CAAX deletion. Beijing Da Xue Xue Bao 2009, 41:516-520.

24. Rikova K, Guo A, Zeng Q, Possemato A, Yu J, Haack H, Nardone J, Lee K, Reeves C, Li Y, Hu Y, Tan Z, Stokes M, Sullivan L, Mitchell J, Wetzel R, MacNeill J, Ren JM, Yuan J, Bakalarski CE, Villen J, Kornhauser JM, Smith B, Li D, Zhou X, Gygi SP, Gu TL, Polakiewicz RD, Rush J, Comb MJ: Global Survey of Phosphotyrosine Signaling Identifies Oncogenic Kinases in Lung Cancer. Cell 2007, 131:1190-1203.

25. Ahn JH, Kim SJ, Park WS, Cho SY, Ha JD, Kim SS, Kang SK, Jeong DG, Jung S$\mathrm{K}$, Lee $\mathrm{S}-\mathrm{H}$ : Synthesis and biological evaluation of rhodanine derivatives as PRL-3 inhibitors. Bioorg Med Chem Lett 2006, 16:2996-2999.
26. Ostman A, Hellberg C, Bohmer FD: Protein-tyrosine phosphatases and cancer. Nat Rev Cancer 2006, 6:307-320.

27. Hunter T: Signaling-2000 and beyond. Cell 2000, 100:113-127.

28. Neel BG, Tonks NK: Protein tyrosine phosphatases in signal transduction. Curr Opin Cell Biol 1997, 9:193-204.

29. Al-Aidaroos AQO, Zeng Q: PRL-3 phosphatase and cancer metastasis. Cell Biochem 2010, 111:1087-1098.

30. Wu X, Zeng H, Zhang X, Zhao Y, Sha H, Ge X, Zhang M, Gao X, Xu O: Phosphatase of regenerating liver-3 promotes motility and metastasis of mouse melanoma cells. Am J Pathol 2004, 164:2039-2054.

31. Saha S, Bardelli A, Buckhaults P, Velculescu VE, Rago C, St Croix B, Romans KE, Choti MA, Lengauer C, Kinzler KW, Vogelstein B: A Phosphatase Associated with Metastasis of Colorectal Cancer. Science 2001, 294:1343-1346.

32. Miskad UA, Semba S, Kato H, Matsukawa Y, Kodama Y, Mizuuchi E, Maeda N Yanagihara K, Yokozaki H: High PRL-3 expression in human gastric cancer is a marker of metastasis and grades of malignancies: an in situ hybridization study. Virchows Archiv 2007, 450:303-310.

33. Moser M, Legate KR, Zent R, Fassler R: The tail of integrins, talin, and kindlins. Science 2009, 324:895-899.

34. Sakai T, Jove R, Fassler R, Mosher DF: Role of the cytoplasmic tyrosines of beta $1 \mathrm{~A}$ integrins in transformation by v-src. Proc Natl Acad Sci U S A 2001, 98:3808-3813

35. Tapley P, Horwitz A, Buck C, Duggan K, Rohrschneider L: Integrins isolated from Rous sarcoma virus-transformed chicken embryo fibroblasts. Oncogene 1989, 4:325-333.

36. Oxley CL, Anthis NJ, Lowe ED, Vakonakis I, Campbell ID, Wegener KL: An integrin phosphorylation switch: the effect of beta3 integrin tail phosphorylation on Dok1 and talin binding. J Biol Chem 2008, 283:5420-5426.

37. Bledzka K, Bialkowska K, Nie H, Qin J, Byzova T, Wu C, Plow EF, Ma YQ: Tyrosine phosphorylation of integrin beta3 regulates kindlin-2 binding and integrin activation. J Biol Chem 2010, 285:30370-30374.

38. Plantefaber LC, Hynes RO: Changes in integrin receptors on oncogenically transformed cells. Cell 1989, 56:281-290.

39. McParland V, Varsano G, Li X, Thornton J, Baby J, Aravind A, Meyer C, Pavic K, Rios P, Kohn M: The metastasis-promoting phosphatase PRL-3 shows activity toward phosphoinositides. Biochemistry 2011, 50:7579-7590.

doi:10.1186/1471-2091-13-22

Cite this article as: Tian et al:: Phosphatase of regenerating liver-3 directly interacts with integrin $\beta 1$ and regulates its phosphorylation at tyrosine 783. BMC Biochemistry 2012 13:22.

\section{Submit your next manuscript to BioMed Central and take full advantage of:}

- Convenient online submission

- Thorough peer review

- No space constraints or color figure charges

- Immediate publication on acceptance

- Inclusion in PubMed, CAS, Scopus and Google Scholar

- Research which is freely available for redistribution 